\title{
The word frequency effect in recognition memory versus repetition priming
}

\author{
SACHIKO KINOSHITA \\ Macquarie University, Sydney, New South Wales, Australia
}

\begin{abstract}
The role of word frequency in recognition memory and repetition priming was investigated by using a manipulation of attention. In Experiment 1, the lexical decision task produced greater repetition priming for low-frequency words than for high-frequency words following either the attended or the unattended study condition. The recognition memory test, on the other hand, showed a low-frequency word advantage only following the attended study condition. Furthermore, this advantage was limited to the measure of recognition memory based on conscious recollection of the study episode. In Experiment 2, a speeded recognition memory test replicated the pattern obtained with the unspeeded recognition memory test in Experiment 1 . These results argue against the view that the word frequency effects in recognition memory and repetition priming have the same origin. Instead, the results suggest that the word frequency effect in recognition memory has its locus in conscious recollection.
\end{abstract}

Word frequency is a variable that has a reliable effect on recognition memory tests: Low-frequency words are recognized better than high-frequency words (see, e.g., Duchek \& Neely, 1989; Glanzer \& Adams, 1985; Gregg, 1976). Word frequency also modulates the amount of repetition priming effects in some indirect memory tests; that is, facilitation due to prior exposure is greater for low-frequency words than for high-frequency words under conditions that do not make any reference to the earlier exposure. This pattern has been found in data-driven indirect tests, the performance on which is assumed to be guided largely by the stimulus features; such tasks include lexical decision (Forster \& Davis, 1984, Experiment 3; Kinoshita, 1989, Experiment 1; Scarborough, Cortese, \& Scarborough, 1977), naming (Skinner \& Grant, 1992), perceptual identification (Jacoby \& Dallas, 1981), and word fragment and word stem completion (MacLeod, 1989; Roediger, Weldon, Stadler, \& Riegler, 1992). ${ }^{1}$

Given this pattern, it seems natural to look for a common basis for the word frequency effects in recognition memory and repetition priming. Recognition memory judgment is generally assumed to involve two components: a component based on conscious recollection of the study episode, and another based on feelings of familiarity (Jacoby \& Dallas, 1981; Mandler, 1980). A commonly held view is that prior exposure facilitates fluency of processing, and that this facilitation in perceptual fluency in turn

This research was supported by the Australian Research Council Grant and the Macquarie University Research Grant to $S$. K. Thanks are due Richard Castles for testing subjects. I am also grateful to the action editor, Mike Masson, and the reviewers (two anonymous, and Eyal Reingold) for their helpful comments on the earlier versions of the manuscript. The stimulus materials used as well as the raw data are available in the ASCII format. Correspondence should be addressed to S. Kinoshita, School of Behavioural Sciences, Macquarie University, Sydney, NSW Australia 2109 (e-mail: sachiko@bunyip.bhs.mq.edu.au). enhances the feeling of familiarity with the item. Because low-frequency items, by definition, are normally processed less fluently than high-frequency items, the increment in fluency due to prior exposure is proportionally greater for low-frequency than for high-frequency words. In this view, the word frequency effects in repetition priming and recognition memory are assumed to have their origins in a common perceptual fluency component.

The pattern of data observed with amnesic Korsakoff patients is consistent with the preceding view. Korsakoff patients, like memory-intact subjects, show greater repetition priming effects of low-frequency words than of highfrequency words in the lexical decision task (Verfaellie, Cermak, Letourneau, \& Zuffante, 1991). In recognition memory tests, Korsakoff patients have shown better performance with low-frequency words than with highfrequency words (Huppert \& Piercy, 1976; Verfaellie et al., 1991). Because amnesic subjects perform poorly on tests that require conscious recollection, taken together it seems most parsimonious to interpret these findings in terms of a common perceptual fluency component intact in amnesic subjects that underlies both repetition priming and feelings of familiarity.

However, recent findings reported by Gardiner and Java (1990), who used a procedure that specifically taps different bases of recognition memory, cast doubt on the view that the same mechanism is responsible for the word frequency effect found on recognition memory tests for memory-intact subjects. In this procedure, originally developed by Tulving (1985), subjects are asked to distinguish between two types of "old" responses in a recognition memory test: remember responses, which are accompanied by conscious recollections of the item's prior occurrence, and know responses, which are not. A series of studies by Gardiner and his associates (1988; Gardiner \& Java, 1990; Gardiner \& Parkin, 1990) have shown dissociative effects of factors on the two measures. For example, Gardiner 
(1988) reported that levels-of-processing and generateversus-read-study manipulations influenced remember responses but not know responses, which is consistent with the view that these manipulations affect conceptually driven operations that are associated with conscious recollection (cf. Roediger \& Blaxton, 1987). Gardiner and Java (1990) observed that the word frequency effect was found with the remember responses but not with the know responses, and hence argued that there was no evidence that the word frequency effect on recognition memory tests reflects greater enhancement of perceptual fluency or familiarity for low- than for high-frequency words.

It may be premature, however, to rule out a role for a common perceptual fluency component in the word frequency effect observed in recognition memory and repetition priming. Given that there are two bases for making recognition memory judgments, a correlation between repetition priming and recognition memory would be reduced when subjects rely on conscious recollection for making recognition memory judgments (Whittlesea, Jacoby, \& Girard, 1990). Recent studies have shown that subjects rely on perceptual fluency for making recognition memory judgments under limited conditions. For example, Johnston, Hawley, and Elliott (1991) found a correlation between the ease of identification of a word and the probability of old judgments following a shallow study (vowel counting) but not following a deep study (word naming) condition. They also failed to find an effect of experimenterinduced manipulation of perceptual fluency on the probability of old judgments (see also Watkins \& Gibson, 1988, for a failure to find an effect of experimenter-induced perceptual fluency). Johnston et al. concluded that perceptual fluency contributes to recognition memory judgments when it is produced naturally and when explicit memory is minimal. Gardiner and Java (1990) used a relatively long study duration $(2 \mathrm{sec})$, and their subjects were given intentional memory instructions. This was likely to have produced high levels of conscious recollection, and subjects may therefore have relied predominantly on this component rather than on perceptual fluency in making recognition memory judgments. The fact that the number of remember responses exceeded know responses is consistent with this view. Thus it is still possible that under a condition in which explicit recollection is minimal, a word frequency effect may be found with know responses.

The aim of the present study was to investigate the relationship between the word frequency effects in repetition priming and in recognition memory. It was expected that a direct link is more likely to be found under conditions that produce little conscious recollection of the study episode and hence when subjects are more likely to rely on feelings of familiarity for making recognition memory judgments. To this end, attention to the target words at study was manipulated.

Before the manipulation is described, the choice of using attention as a variable must be defended. This decision was motivated by a study in which Merikle and Reingold (1991) found that an indirect test of memory (judging the clarity of a word presented against a mask) was more sensitive than a direct test of memory (recognition memory test) to prior exposure when the targets were not attended to during study. Merikle and Reingold took this finding to suggest that subjects were more likely to rely on perceptual fluency than explicit recollection when words were not consciously attended to at study. However, contrary to this view, Gardiner and Parkin (1990) reported that dividing attention at encoding reduced only the number of remember responses and not the know responses; they thus argued that attention affects only conscious recollection.

There are some comments to be made against Gardiner and Parkin's (1990) claim, however. First, in their study, although the number of know responses was unaffected by the manipulation of attention, the ratio of know responses to overall old judgments was greater in the divided attention condition than in the focused attention condition (because the number of remember responses decreased, and the number of know responses was unchanged). Rajaram (1993) has made the point that given the nature of instruction that requires subjects to respond know when they fail to make a remember response, remember and know responses cannot be considered to be independent, and therefore the ratio, rather than the number of responses, may be a more appropriate index of which process subjects rely on in making recognition memory judgments. When this measure is used, Gardiner and Parkin's (1990) data are consistent with the view that dividing attention increases the reliance on perceptual fluency. Second, there were more remember responses than know responses even in the divided attention condition, suggesting that subjects were still relying predominantly on conscious recollection. Several reasons may be suggested for this. Subjects in the divided attention condition studied each target word for $2 \mathrm{sec}$ with intentional memory instruction while performing a secondary task, which consisted of listening to a sequence of tones and classifying each tone as high, medium, or low in pitch. It has been argued that such a cross-modal secondary task may allow modality-specific attention to operate (Kellogg, 1980). Furthermore, given the duration of presentation and the intentional memory instruction used, the words may have been relatively well encoded. Any of these factors could have still allowed subjects to rely on conscious recollection even under the divided attention condition. In summary, then, Gardiner and Parkin's finding does not rule out the possibility that subjects would show greater reliance on perceptual fluency for making recognition memory judgments when attention to the study items is more limited.

In order to produce minimal attention for words presented during the study phase, a manipulation originally developed by Wolford and Morrison (1980) was used in Experiment 1. In their study, on each trial, subjects were shown a word flanked by two single digits for a brief period (e.g., 3 word 5). In the attended condition, subjects were told to ignore the digits and to make a decision about the word (e.g., whether or not the word had more than six letters). In the unattended condition, subjects were instructed to ignore the word and to decide whether or not the digits were of the same parity (i.e., whether they were 
both odd or both even). Phenomenologically, words in this condition seemed to disappear after a couple of trials. But because carrying out the digit task requires subjects to see both digits, the word must remain centered foveally; hence Wolford and Morrison argued that any success in ignoring it must be accomplished centrally. This manipulation produced evidence that some processing occurred with the unattended material, as attested by the visual equivalent of the cocktail party phenomenon, in which subjects notice their own name inserted in place of the word. Performance on a forced-choice recognition memory test for the unattended words was at chance, suggesting that the attention manipulation produced minimal explicit memory. At the same time, however, confidence ratings for correct recognition trials were higher than those for incorrect trials. It is unclear whether the confidence rating data reflect the perceptual fluency component. In the present experiment, know responses were expected to provide a more specific index of recognition memory based on perceptual fluency for the unattended material.

To summarize, in the present experiment, subjects performed either a lexical decision task or a recognition memory task with high-frequency and low-frequency words following a study phase consisting of the attended and unattended blocks. In the recognition memory test, for the attended words, it was expected that Gardiner and Java's (1990) finding of low-frequency advantage with remember responses but not with know responses would be replicated. For the unattended words, it was assumed that the reliance on conscious recollection would be minimal. This reliance was to be indexed by a lack of difference between the number of remember responses for the unattended words and new words. For the know responses, from the view that the low-frequency advantage in recognition memory reflects only conscious recollection, no low-frequency advantage is expected for know responses either. In contrast, if the word frequency effect in recognition memory has its origin in the perceptual fluency component, there should be more know responses for low-frequency words than for high-frequency words. The lexical decision task was used as an index of perceptual fluency. Relative to new words, lexical decision should be faster for words that are processed more fluently as a result of prior exposure; that is, a repetition priming effect was expected. Further, from the view that relative increment in perceptual fluency is greater for low-frequency than for high-frequency words, repetition priming was expected to be greater for lowfrequency words.

\section{EXPERIMENT 1}

\section{Method}

\section{Recognition Memory Test}

Subjects. Twenty-four undergraduate psychology students at Macquarie University participated in the experiment in return for course credit.

Materials and design. The experiment was a $2 \times 3$ design with frequency (high vs. low) and study status (attended, unattended, and new) as within-subject variables. A set of 96 words, 48 high frequency and 48 low frequency, was selected from the Medical Re- search Council (MRC) psycholinguistic database described by Coltheart (1981). All words were five letters long. The high-frequency words ranged between 72 and 787 occurrences per million and had a mean frequency count of 188.3; the low-frequency words ranged between 0 and 5 occurrences per million and had a mean frequency count of 2.6 in Kučera and Francis's (1967) frequency count. The high- and low-frequency words had mean imagery values of 513.8 and 509.8 , respectively, as calculated by the MRC database by merging three sets of norms to form a scale ranging from 100 to 700 . Examples of high-frequency words are young, speak, earth, floor, and white. Examples of low-frequency words are yacht, sleet, lunge, sting, and badge.

The pool of words was divided into three sets, A, B, and C, each consisting of 16 high- and 16 low-frequency words, matched on average frequency and imagery values. Across every 3 subjects, each set was assigned once to one of the three experimental conditions: attended, unattended, and new. The recognition test consisted of all 96 words in the set.

Procedure. The experiment had two phases: study and test. Each study phase consisted of the attended and unattended blocks. Half of the subjects did the attended block first, and the other half did the unattended block first. Stimulus presentation was controlled by the dmastr software developed by Forster and Forster (1990). Subjects were seated individually in front of an NEC Multisync 4FG Monitor interfaced to an IBM-compatible personal computer. They were instructed that on each trial they would see a word flanked by two digits. In the attended block, they were instructed to ignore the digits and read the word aloud. In the unattended block, they were to ignore the word and decide as quickly as possible whether or not the digits were of the same parity (i.e., both odd or both even), and to press (1) the key marked " + " on the response pad if they were the same or (2) the key marked "-" if they were different. Each trial started with a fixation point $\left({ }^{*}\right)$ centered on the screen. Five hundred milliseconds later, a word flanked by two digits replaced the fixation point and remained on the screen for $100 \mathrm{msec}$. The next trial started 2 sec later. A different random order was generated for each subject. A short practice session composed of 8 trials preceded each block. Each block had 2 initial buffer trials and 32 test trials. The subjects were not told about the subsequent recognition memory test.

The test phase followed immediately after the study phase. The subjects were told that they would be given a response sheet with a list of 96 words and that they were to decide whether or not it was one of the study items. They were asked to circle items they recognized from the study phase. In addition, for each item recognized, they were asked to respond either "remember" or "know." It was explained that if they could recollect some aspect of the study episode in which the word was presented (e.g., what digits flanked it, what it looked like, etc.), they should respond "remember." If they thought the word was presented in the study phase but could not recollect any aspect of the episode, they were to respond "know." Each experimental session lasted approximately $20 \mathrm{~min}$.

\section{Lexical Decision Task}

Subjects. An additional 24 subjects from the same population as that used for the recognition memory test participated in this task. None of the subjects had participated in the recognition memory test.

Design and Materials. The study lists were identical to those used in the recognition memory test. In addition, in the lexical decision task, 64 nonwords were used. The nonwords, all five letters long, were generated by changing one or two letters of five-letter words in the MRC psycholinguistic database. Examples are nonor, bozen, spuke, boyer, vaudy. In the lexical decision task, the 96 high- and 48 low-frequency words and the 64 nonwords were mixed in different random order for each subject. There was also a practice list consisting of four words and four nonwords, and two initial buffer items (all five letters long) that were not included in the analysis.

Procedure. This portion of the experiment had two phases: study and the lexical decision task. The procedure for the study phase was 
identical to that in the recognition memory test. The lexical decision task followed immediately after the completion of the study phase. The subjects were told that they would now see a list of letter strings and that their task was to decide for each string whether or not it was an English word. They were instructed to press the "+" button if the string was a word and the "- " button if it was not a word, as soon as they could decide.

The subjects were given a practice block of 8 trials, followed by a test block of 162 trials, including two initial buffer items that were not included in the analysis. On each trial, a letter string was presented for $500 \mathrm{msec}$. The subjects were given $2 \mathrm{sec}$ to respond. The next trial began $1 \mathrm{sec}$ after the subject responded. The reaction time was measured to the nearest millisecond.

\section{Results \\ Recognition Memory Test}

The proportion of recognized items is presented in Figure 1. For the attended and unattended conditions, this proportion represents the hit rate, and for the new condition, it represents the false alarm rate.

Separate analyses of variance (ANOVAs) were carried out for remember responses and know responses for targets with frequency (high vs. low) and study status (attended, unattended, and new) as factors. Remember and know responses were not treated as two levels of an independent variable, as they were in Gardiner and Java (1990; see also Rajaram, 1993). An effect was considered to be significant at the .05 level.

For remember responses, the main effect of frequency was significant $\left[F(1,23)=38.17, M S_{\mathrm{e}}=36.972\right]$, indicating that more remember responses were made to lowfrequency words than to high-frequency words. The main effect of study status was also significant $[F(2,46)=149.45$, $\left.M S_{\mathrm{e}}=5.420\right]$. Contrasts testing individual comparisons between each of the attended and unattended conditions with new conditions showed that significantly more responses were made to attended words than to new words $\left[F(1,23)=155.07, M S_{\mathrm{e}}=7.949\right]$, but the contrast between unattended and new conditions was nonsignificant $\left[F(1,23)=1.72, M S_{\mathrm{e}}=.152\right]$. The absence of a significant effect indicated that there was little conscious recollection of unattended words. The interaction between frequency

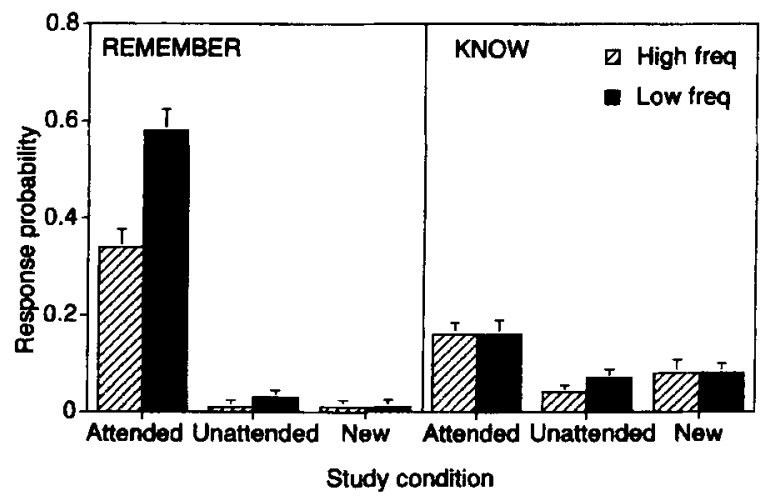

Figure 1. Response probabilities in recognition memory test for high- and low-frequency words. Error bars represent standard errors. and study status was significant $\left[F(2,46)=35.2, M S_{\mathrm{e}}=\right.$ 1.483]. This interaction reflected a greater difference between attended and new words for low-frequency words than for high-frequency words $\left[F(1,23)=38.72, M S_{\mathrm{e}}=\right.$ $2.179]$. The frequency effect did not differ between the unattended and new words $\left[F(1,23)=2.77, M S_{\mathrm{e}}=.184\right]$.

For know responses, the ANOVA showed that the main effect of frequency was nonsignificant $(F<1.0)$. The main effect of study status was significant $[F(2,46)=16.58$, $\left.M S_{\mathrm{e}}=2.232\right]$. Contrasts between the attended and new words showed that significantly more know responses were made in the attended condition than in the new condition $\left[F(1,23)=16.28, M S_{\mathrm{e}}=2.539\right]$. This indicated that the attended and new words could be discriminated on the basis of feelings of familiarity. In contrast, the number of know responses did not differ between unattended and new conditions $\left[F(1,23)=1.31, M S_{\mathrm{e}}=2.293\right]$. The interaction between the effects of frequency and study status was nonsignificant $(F<1.0)$.

\section{Lexical Decision Task}

The mean decision latencies for correct responses are shown in Figure 2, and percentage of error rates are shown in Figure 3. The decision latency and percent error rate were analyzed using a two-way ANOVA with frequency (high vs. low) and study status (attended, unattended, new) as within-subject factors.

For decision latency, the main effect of frequency was significant $\left[F(1,23)=74.70, M S_{\mathrm{e}}=3,882\right]$, indicating that high-frequency words were responded to faster than low-frequency words. The main effect of study status was also significant $\left[F(2,46)=13.49, M S_{\mathrm{e}}=921\right]$. Contrast between the attended words and new words was significant $\left[F(1,23)=20.78, M S_{\mathrm{e}}=1,193\right]$, indicating a faster lexical decision latency for attended words than for new words. The decision latency was also significantly faster for the unattended words than for new words $[F(1,23)=$ $\left.6.91, M S_{\mathrm{e}}=773\right]$. The interaction between study status and frequency was also significant $\left[F(2,46)=3.23, M S_{\mathrm{e}}=\right.$ $1,107]$. The contrast testing the interaction between attended versus new words and frequency was not significant $\left[F(1,23)=2.85, M S_{\mathrm{e}}=1,467\right]$. In contrast, the difference between unattended and new words was significantly greater for low-frequency than for high-frequency words $\left[F(1,23)=5.51, M S_{\mathrm{e}}=1,150\right] .^{2}$

For percent error, the ANOVA showed that the main effect of frequency was significant $[F(1,23)=34.97$, $\left.M S_{\mathrm{e}}=48.523\right]$, indicating a significantly greater error rate for low-frequency words than for high-frequency words. The main effect of study status was also significant $\left[F(2,46)=8.47, M S_{\mathrm{e}}=27.315\right]$. Individual contrasts showed that the error rate for new words was significantly greater than that for attended words $[F(1,23)=12.3$, $\left.M S_{\mathrm{e}}=31.775\right]$, but not greater than that for unattended words $(F<1.0)$. The effects of study status and frequency interacted $\left[F(2,46)=11.58, M S_{\mathrm{e}}=27.503\right]$. The effect of frequency was significantly greater for attended words than for new words $\left[F(1,23)=20.43, M S_{\mathrm{e}}=30.382\right]$. In contrast, the effect of frequency did not differ signifi- 


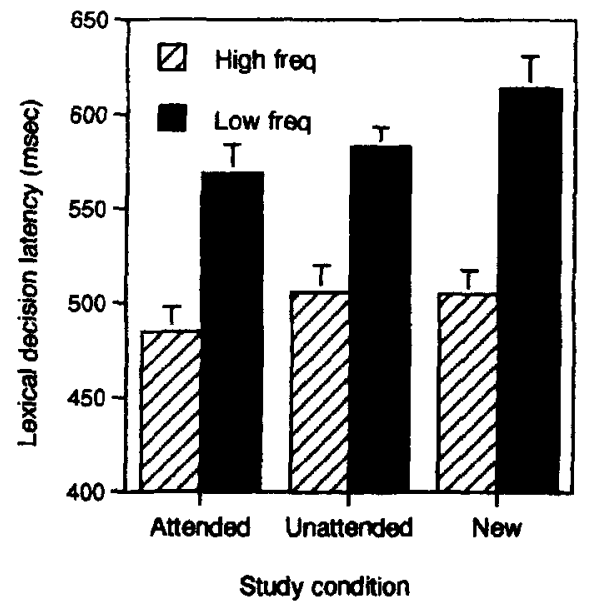

Figure 2. Mean latencies in the lexical decision task for highand low-frequency words. Error bars represent standard errors.

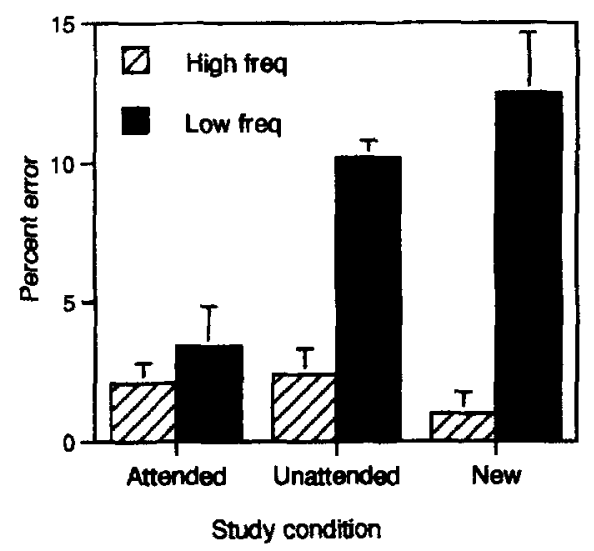

Figure 3. Percent errors in the lexical decision task for highand low-frequency words. Error bars represent standard errors.

cantly for unattended and new words $[F(1,23)=2.43$, $\left.M S_{\mathrm{e}}=32.997\right]$.

To summarize, the lexical decision data showed that a prior exposure of a word, whether attended or unattended, facilitated lexical decision, and that this priming effect was greater for low-frequency words than for high-frequency words (this pattern having been observed with error rate for attended words and latency for unattended words). This priming effect for the unattended words contrasts with the absence of recognition memory for these words, measured by either remember or know responses.

\section{Analysis of the Digit Task}

It is possible that a dissociation in the pattern of effects in the recognition memory test and the lexical decision task for the unattended words was due to the subjects in the two groups paying differential amounts of attention to the words in the study phase. To test this possibility, decision latency and error rates for the digit parity task in the unattended block were examined, using a three-way ANOVA with task group (lexical decision vs. recognition memory) as a between-groups factor and word frequency (high vs. low) and response type (same vs. different parity) as withinsubject factors. The mean response latencies are shown in Figure $\mathbf{4}$ and percent error rates are shown in Figure 5. For decision latency, none of the effects were significant $(F<$ 1.0 in all cases) except the main effect of response type $\left[F(1,46)=34.88, M S_{\mathrm{e}}=15,060\right]$, indicating faster same responses than different responses. For percentage of error rates, the only significant effect was the main effect of word

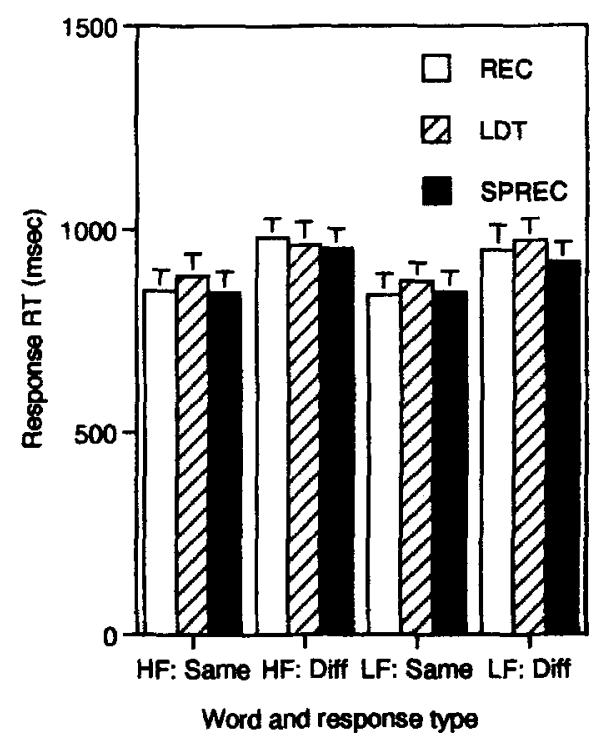

Figure 4. Mean latencies in the digit parity task (REC, recognition memory test group; LDT, lexical decision task group; SPREC, speeded recognition memory test group; HF, high-frequency words; LF, low-frequency words). Error bars represent standard errors.

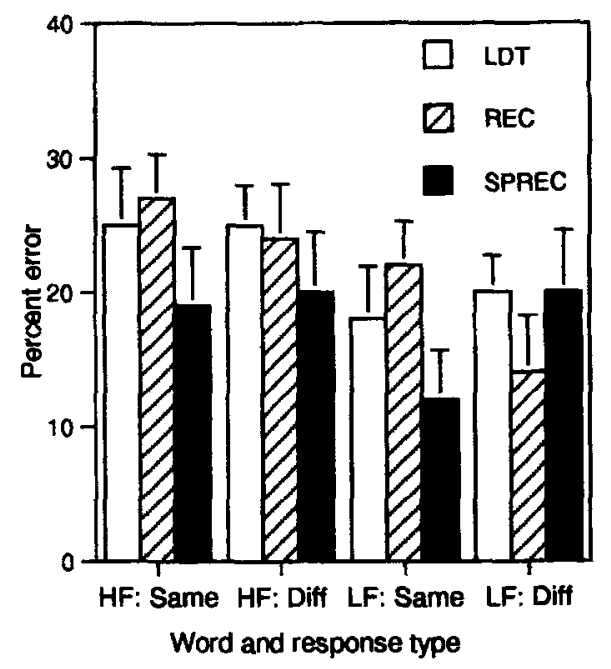

Figure 5. Percent errors in the digit parity task (LDT, lexical decision task group; REC, recognition memory test group; SPREC, speeded recognition memory test group; HF, high-frequency words; LF, low-frequency words). Error bars represent standard errors. 
frequency $\left[F(1,46)=18.33, M S_{\mathrm{e}}=120.02\right]$, indicating higher error rates when a high-frequency word was presented. All other effects were nonsignificant $(F<1.0$ in all cases), but the task group $\times$ word frequency $\times$ response type interaction was significant $\left[F(1,46)=1.60, M S_{\mathrm{e}}=\right.$ 99.50]. Most importantly, there were no significant main effects or interactions involving the task group factor, indicating that there was no evidence that the two groups performed the digit parity task differently.

\section{Discussion}

The main finding of the recognition memory experiment was that the advantage for low-frequency words was found only with remember responses, and that this effect of frequency was found only when the words were actively attended to in the study phase but not when they were not consciously attended to. There was no frequency effect for know responses for either attended or unattended words. The pattern of frequency effects observed with attended words replicated that reported by Gardiner and Java (1990, Experiment 1) and is consistent with the view that the lowfrequency advantage has its origins in conscious recollection. For unattended words, neither remember responses nor know responses discriminated between these words and new words, suggesting that recognition performance based on either conscious recollection or perceptual fluency was at chance level. Although the chance-level conscious recollection for unattended words was entirely expected, the pattern observed with know responses was contrary to the prediction that subjects would rely on perceptual fluency for making recognition memory judgments when explicit memory was minimal.

In contrast to the absence of recognition memory for unattended words, the lexical decision data provided evidence that unattended words were processed more fluently at test. The main finding of this task was that repetition priming was observed following both the attended and the unattended conditions, and that priming was greater for low-frequency words than for high-frequency words following either attention condition. This pattern of finding therefore suggests that attention is not a prerequisite for low-frequency words to benefit from prior exposure more than high-frequency words.

The recognition memory data and the lexical decision data therefore showed a dissociation in the pattern of interaction between the effects of attention manipulation and word frequency. Whereas the lexical decision data suggest that low-frequency words benefited more from prior exposure than did high-frequency words whether or not the word was consciously attended to, the recognition memory data suggest that only the component assumed to tap conscious recollection showed better performance for low-frequency words, and that this low-frequency advantage was found only when the words were consciously attended to.

Findings of dissociation between a direct and an indirect test of memory for materials that are not consciously apprehended are not new. In a well-known study, KunstWilson and Zajonc (1980) reported that repeated prior ex- posure of irregular polygons for very brief durations produced chance-level recognition memory judgments but reliably affected preference judgments. Mandler, Nakamura, and van Zandt (1987) extended this finding to judgments of brightness and darkness. Eich (1984) found a spelling bias for homophones presented on an unattended channel that were consistent with the modifier (e.g., taxi-FARE) despite chance-level recognition memory judgment for these words. The present finding of repetition priming effects in the lexical decision task for unattended words in the absence of recognition memory is entirely consistent with these findings. However, in the previous studies, no distinction was made between recognition memory based on conscious recollection as opposed to other sources. In the present study, the know responses were assumed to provide an index of the second type of recognition memory, based on perceptual fluency. The results, contrary to the prediction, provided little evidence that subjects used perceptual fluency as a basis for discriminating between old (unattended) and new words despite evidence of the enhancement of discrimination observed with the lexical decision task.

\section{EXPERIMENT 2}

It might be argued that the dissociation observed between the recognition memory test and the lexical decision task in Experiment 1 reflects the requirement to make speeded decisions in the latter task. Within some models (e.g., Atkinson \& Juola, 1974; Gillund \& Shiffrin, 1984), different bases for making recognition memory judgments are assumed to have different time courses. Specifically, feelings of familiarity are generally assumed to affect early stages. Perhaps subjects did not use perceptual fluency as a basis because they were given unlimited time for making recognition memory judgments.

To test this possibility, in Experiment 2 the attention manipulation and stimulus materials used on the recognition memory test in Experiment 1 were employed again, except that subjects were required to respond as fast as possible. It was expected that under time pressure, subjects might make greater use of perceptual fluency in making recognition memory judgments, and hence that the pattern of data would resemble that observed with the lexical decision task - that is, a discrimination between unattended words and new words, and for these words, greater recognition memory for low-frequency than for high-frequency words. In addition, following Rajaram (1993), after each speeded recognition memory judgment, subjects responded "remember" or "know" without time pressure. To the extent that know responses were assumed to tap feelings of familiarity, know responses (but not remember responses) were expected to mirror the pattern of data for speeded recognition memory judgments.

\section{Method}

Subjects. An additional 24 undergraduate psychology students at Macquarie University participated in the experiment, in return for course credit. 
Materials and Design. The experiment was a $2 \times 3$ design with frequency (high vs. low) and study status (attended, unattended, and new) as within-subject variables. The stimulus materials were identical to those in Experiment 1.

Procedure. The experiment had two phases: study and test. The study phase was identical to that of Experiment 1. In the test phase, which followed immediately after the study phase, the subjects were told that they would be presented with a list of words on the computer screen, and they were instructed to decide as quickly as possible whether or not each word had been presented earlier. The subjects were instructed to.press the key marked "+" if the word had been presented earlier, irrespective of whether it was to be attended to or ignored, and to press the key marked "- " if it had not been presented earlier. In addition, for each item, subjects were asked to respond "remember," "know," or "new." The instructions for remember and know responses were identical to those in Experiment 1 . The subjects made their responses orally, and the experimenter recorded the responses on a response sheet. Each experimental session lasted approximately $20 \mathrm{~min}$.

\section{Results}

Although both response latency and accuracy were measured, for 7 subjects the response latency data for the unattended words could not be obtained, because these subjects rejected either all of the high-frequency or all of the low-frequency unattended words as new. Given that the latency measure is based on the performance of the remaining 17 subjects, it is reported for completeness, and it will not be discussed further (other than to point out that the pattern of the latency data is consistent with the probability of old responses).

The mean decision latencies and probabilities of speeded old responses are presented in Figures 6 and 7, respectively, and the proportions of remember and know responses are presented in Figure 8. It should be noted that the proportion of speeded old responses was smaller than the sum of remember and know responses for attended and unattended words and greater for new words, indicating that subjects corrected themselves when allowed to make

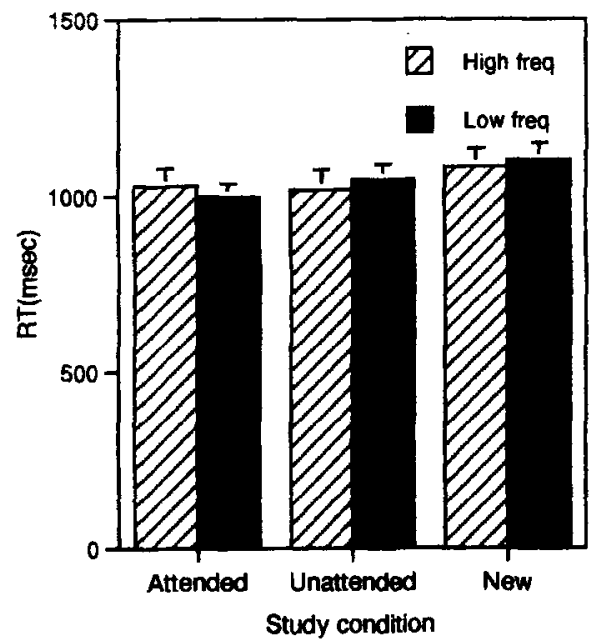

Figure 6. Mean latencies in the speeded recognition memory test for high- and low-frequency words. Error bars represent standard errors.

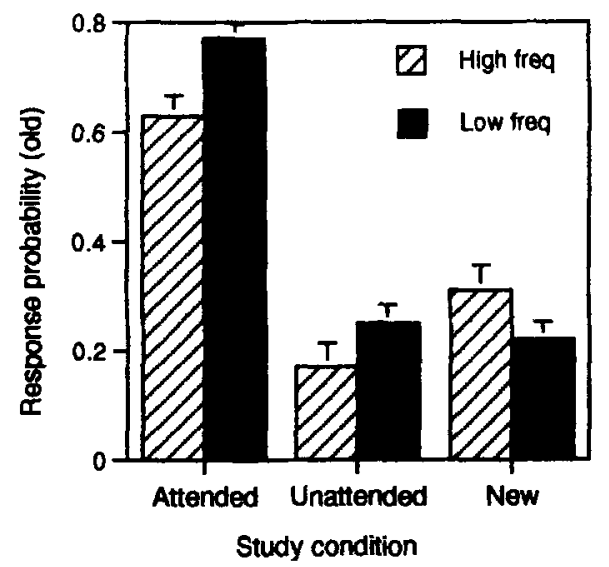

Figure 7. Response probabilities in the speeded recognition memory test for high- and low-frequency words. Error bars represent standard errors.

decisions without time pressure. However, as will be seen in the analysis, more know responses were made on the speeded test than on the unspeeded test in Experiment 1, suggesting that the requirement to make speeded decisions increased the reliance on feelings of familiarity, as was assumed.

As in Experiment 1, a two-way ANOVA was used, with frequency (high vs. low) and study status (attended, unattended, and new) as within-subject factors.

For the speeded decision latency data, none of the effects was significant $(F<1.0$ in all cases). The lack of significance is due to large variability across subjects, but as will be seen below, the pattern of data observed in Figure 6 is consistent with the probability-of-old-responses measure.

For probability of speeded old responses, the main effect of frequency was nonsignificant $(F<1.0)$. The main effect of study status was significant $\left[F(2,46)=119.65, M S_{\mathrm{e}}=\right.$ 2.55]. Individual contrasts showed that more old responses were made to attended words than to new words $[F(1,23)=$ $\left.132.38, M S_{\mathrm{e}}=3.42\right]$, but the difference between unattended and new words was nonsignificant $(F<1.0)$. The interaction between frequency and study status was also significant $\left[F(2,46)=16.95, M S_{\mathrm{e}}=1.02\right]$. Individual contrasts showed that this interaction reflected a greater difference between attended and new words for low-frequency words than for high-frequency words $[F(1,23)=30.74$, $\left.M S_{\mathrm{e}}=1.07\right]$, but the unattended and new words did not differ in the magnitude of the frequency effect $[F(1,23)=$ 2.82, $\left.M S_{\mathrm{e}}=.97\right]$.

For remember responses, the main effect of frequency was significant $\left[F(1,23)=22.39, M S_{\mathrm{e}}=2.188\right]$, indicating an advantage for low-frequency words. The main effect of study status was also significant $[F(2,46)=64.85$, $\left.M S_{\mathrm{e}}=6.938\right]$. Individual contrasts showed that significantly more remember responses were made to attended words than to new words $\left[F(1,23)=66.28, M S_{\mathrm{e}}=10.38\right]$, but that the contrast between unattended and new words was nonsignificant $(F<1.0)$. The interaction between frequency and study status was significant $[F(2,46)=25.94$, 


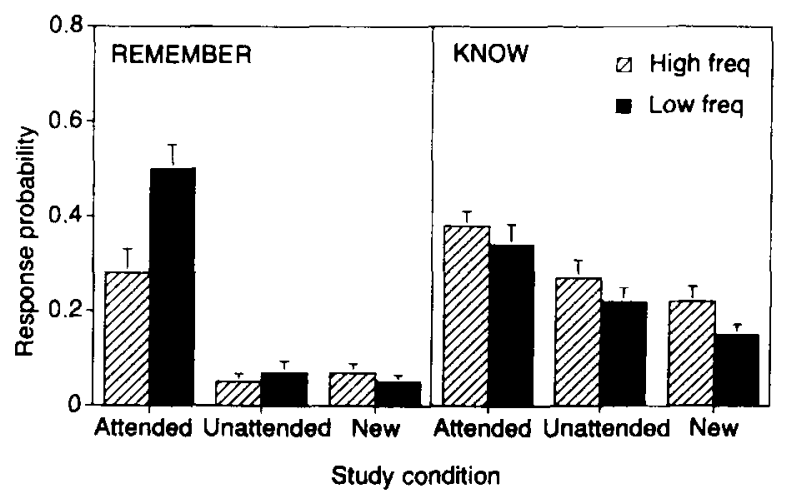

Figure 8. Response probabilities in the speeded recognition memory test for high- and low-frequency words. Error bars represent standard errors.

$\left.M S_{\mathrm{c}}=1.856\right]$. Individual contrasts showed that this interaction reflected a greater low-frequency advantage with atended words than with new words $[F(1,23)=32.59$, $\left.M S_{\mathrm{e}}=2.532\right]$, but that the word frequency effect did not differ significantly between the unattended and new words $\left[F(1,23)=2.32, M S_{\mathrm{e}}=.76\right]$.

For know responses, the main effect of frequency was significant $\left[F(1,23)=8.20, M S_{\mathrm{e}}=3.36\right]$, indicating an advantage for high-frequency words. The main effect of study status was significant $\left[F(2,46)=10.46, M S_{\mathrm{e}}=\right.$ 8.881 ]. Individual contrasts showed significantly more know responses to attended words than to new words $\left[F(1,23)=15.40, M S_{\mathrm{e}}=11.608\right]$, and to unattended words than to new words $\left[F(1,23)=6.07, M S_{\mathrm{e}}=3.173\right]$. The interaction of study status and frequency was nonsignificant $(F<1.0)$.

In summary, even with the requirement to make speeded recognition memory decisions, a low-frequency advantage was found only with attended words, not with unattended words.

\section{Comparison With the Unspeeded Test}

In order to compare the patterns of remember and know responses on the speeded tests with those on the unspeeded tests, a three-way ANOVA was carried out with task group (unspeeded vs. speeded) as a between-groups factor and attention (attended vs. unattended) and frequency (high vs. low) as within-subject factors.

For remember responses, the main effect of task group was nonsignificant $(F<1.0)$. The main effect of attention was significant $\left[F(1,46)=205.28, M S_{\mathrm{e}}=8.862\right]$, indicating more remember responses to the attended words than to the unattended words. This effect interacted with task group $\left[F(1,46)=4.45, M S_{\mathrm{e}}=8.862\right]$, indicating that the difference between attended and unattended words was greater for the unspeeded group than for the speeded group. The main effect of frequency was significant $[F(1,46)=$ $\left.64.13, M S_{\mathrm{e}}=2.78\right]$, indicating an advantage for lowfrequency words. The interaction effect between attention and frequency was also significant $[F(1,46)=60.37]$, indicating that the low-frequency advantage is found with attended words and not with unattended words. None of the other effects were significant $(F<1.0$ in all cases).

For know responses, the main effect of task group was significant $\left[F(1,46)=45.05, M S_{\mathrm{e}}=10.267\right]$. This reflected the fact that the speeded group made more know responses than did the unspeeded group. The main effect of attention was also significant $\left[F(1,46)=21.42, M S_{\mathrm{e}}=\right.$ $6.862]$, indicating that more know responses were made with attended words than with unattended words. The task group $\times$ frequency interaction approached, but did not reach, significance $\left[F(1,46)=3.86, M S_{\mathrm{e}}=2.858, p=\right.$ $.056]$. This reflected the trend that the speeded group tended to make more know responses to high-frequency words than to low-frequency words, whereas the unspeeded group did not. None of the other effects were significant $(F<1.0$ in all cases), except for the main effect of frequency $\left[F(1,46)=1.23, M S_{\mathrm{e}}=2.858\right]$.

The comparison between the unspeeded and speeded recognition memory tests showed that the speeded group exhibited greater reliance on feelings of familiarity than did the unspeeded group, as is evidenced by the greater number of know responses overall and fewer remember responses for the attended words. Despite this, the pattern of the word frequency effect was the same in the two groups, indicating that the low-frequency advantage is found with attended words but not with unattended words, and with only remember responses and not with know responses. Importantly, the speeded old responses mirrored the pattern obtained with remember responses and not know responses, providing little support for the view that a lowfrequency advantage would emerge with know responses with the requirement to make speeded decisions.

\section{Analysis of the Digit Task}

As in Experiment 1, subjects' performance on the digit parity task in the unattended condition was compared with that of the group given the lexical decision task in Experiment 1 . The mean response latencies and error rates are shown in Figures 4 and 5. These two dependent variables were subjected to a three-way ANOVA with task group (lexical decision task vs. speeded recognition memory test) as a between-groups factor and word frequency (high vs. low) and response type (same vs. different) as within-subject factors. For response latency, except for the main effect of response type $\left[F(1,46)=51.01, M S_{\mathrm{e}}=10,655\right]$, all main effects or interactions were nonsignificant $(F<1.0$ in all cases), except for the main effect of frequency $[F(1,46)=$ $\left.3.26, M S_{\mathrm{e}}=4,953\right]$ and the interaction of word frequency and response type $\left[F(1,46)=1.29, M S_{\mathrm{e}}=6,945\right]$. As in Experiment 1, subjects were slower with different responses than with same responses. For percentage of error rate, the only significant effect was the main effect of word frequency $\left[F(1,46)=9.63, M S_{\mathrm{e}}=163.61\right]$, with higher error rates when the digits flanked a high- rather than a low-frequency word. None of the other effects was significant $(F<1.0$ in all cases), but there were significant interactions of task group $\times$ response type $\left[F(1,46)=2.99, M S_{\mathrm{e}}=436.76\right]$ and task group $\times$ word frequency $\times$ response type $[F(1,46)$ $\left.=3.55, M S_{\mathrm{e}}=132.19, p=.066\right]$. Since none of the main 
effects or interactions involving the task group factor were significant, it can be concluded that the dissociation in the pattern of effects of attention and word frequency in the two tasks cannot be due to a differential amount of attention paid to the unattended words by the two groups.

\section{GENERAL DISCUSSION}

The present experiments were performed in order to investigate the locus of the word frequency effect in recognition memory. To test the view that the effect has the same origin as does the low-frequency word advantage in repetition priming, the effects of manipulating attention at encoding on a recognition memory test were compared with the effects of manipulating attention at encoding in a lexical decision task. In Experiment 1, there was minimal recognition memory (based either on conscious recollection or on feelings of familiarity as tapped by remember and know responses, respectively) for words that were not attended to in the study phase, even though the same words showed repetition priming effects in a lexical decision task. Furthermore, repetition priming found with these words was greater for low-frequency words than for highfrequency words, suggesting that attention at encoding is not a prerequisite for observing greater benefit of preexposure for low- than for high-frequency words. For words that were attended to, a low-frequency word advantage was found in the recognition memory task, but this was confined to a measure that is assumed to tap conscious recollection (remember responses). To test the possibility that the dissociation in the pattern of word frequency effects in recognition memory and repetition priming was due to the requirement to make speeded decisions, a speeded recognition memory test was used in Experiment 2. Although subjects showed greater reliance on feelings of familiarity in the speeded test, the pattern of word frequency effects did not differ from that in Experiment 1 . That is, low-frequency word advantage was confined to attended words and to remember responses. This means that the difference in the pattern of word frequency effects in the lexical decision task and the recognition memory judgment could not be attributed to the requirement to make speeded decisions. These results instead indicate that the word frequency effect in recognition memory has its origin in conscious recollection.

It might be argued that the present claim depends critically on the validity of the remember/know measures. At least two issues need to be considered in this regard, and these will be discussed below: (1) the sensitivity of the know measure, and (2) the possibility that subjects make remember/know judgments for low- and high-frequency words on different bases. ${ }^{3}$

The present claim that the word frequency effect in recognition memory cannot be attributed to greater increment in perceptual fluency for low-frequency words is based on the absence of a low-frequency advantage for know responses in the unattended condition. Given that the probability of know responses was generally low in this condition, it may be that a floor effect masked a low-frequency advantage. To check this possibility, $t$ tests were carried out to determine whether the probability of know responses in the unattended condition differed significantly from zero. The probabilities were all significant: in Experiment 1, for high-frequency words $[t(1,23)=2.798, p<.02]$, and for low-frequency words $[t(1,23)=3.871, p<.01]$; and in Experiment 2, for high-frequency words $[t(1,23)=7.078$, $p<.01]$, and for low-frequency words $[t(1,23)=7.299$, $p<.01]$. Hence, the absence of a word frequency effect cannot be attributed to a floor effect.

It might still be argued that the fact that in Experiment 1 know responses did not differ between unattended and new words represents a functional floor effect that may have masked a potential low-frequency advantage for know responses. Although this is true for Experiment 1, Experiment 2 did show that know responses differed between unattended and new words. Therefore, the absence of an advantage for low-frequency words for know responses in this experiment cannot be explained solely in terms of a floor effect.

It should be noted that ruling out a potential floor effect does not preclude the possibility that know responses may be generally less sensitive than remember responses. Indeed, a number of the manipulations reported by Gardiner and his associates (Gardiner, 1988; Gardiner \& Java, 1990; Gardiner \& Parkin, 1990) affected remember responses but had little effect on know responses (e.g., levels-of-processing, generate-vs.-read manipulation, and retention interval). However, there are factors that affect know responses but not remember responses, such as masked repetition priming of test targets (Rajaram, 1993). Thus it seems unlikely that know responses are a priori less sensitive than remember responses to a given manipulation and hence failed to reveal a low-frequency word advantage. In summary, it can be argued that the failure to find an advantage for low-frequency words for know responses in the present study cannot be attributed solely to a potential floor effect.

That subjects use different bases for making remember/ know judgments for high- and low-frequency words is another possibility that might challenge the current claim. Specifically, the argument is that a feeling for familiarity for low-frequency words is more likely to be classified as remember, relative to a feeling of familiarity concerning high-frequency words, because a feeling of familiarity is likely to be more diagnostic of a recent encounter for lowfrequency words than for high-frequency words. It is consistent with this possibility that in Experiment 2 the probability of know responses for new words was higher for high-frequency words than for low-frequency words (see the right-hand panel of Figure 8). Such a bias could then have masked a low-frequency advantage for know responses that has its origin in perceptual fluency. Furthermore, if subjects were instructed to be more strict in classifying as a remember response only those items regarding which they were certain to have had a recollective experience, then a low-frequency word advantage might have emerged for the know responses.

It must be acknowledged that there is nothing in the current data (nor in previous research obtained with remember/ 
know responses) to refute the possibility that subjects used different bases for making remember and know responses for different types of items. However, in arguing that a feeling of familiarity for low-frequency words is less likely to be assigned to know responses than is a feeling of familiarity for high-frequency words, one is making the claim that know responses do not directly mirror perceptual fluency. Such a claim is then essentially in agreement with the present view, to the extent that the origin of the word frequency effect in recognition memory is assumed not to be in perceptual fluency. The difference between the two views would be that whereas the current view would regard the word frequency effect observed with remember responses as reflecting its origin in conscious recollection, the alternative view would interpret this as simply reflecting a differential attributional bias for high- and low-frequency words. However, the magnitude of the low-frequency advantage observed with remember responses (in either Experiment 1 or 2 ) is far larger than the high-frequency advantage (when it is observed) with know responses in any of the study conditions, suggesting that the word frequency effect observed with remember responses was unlikely to be due solely to an attributional bias. At least some of the low-frequency word advantage observed with remember responses must be due to conscious recollection.

The interpretation that the word frequency effect in recognition memory reflects conscious recollection and not perceptual fluency is consistent with earlier research suggesting that it is a modality-independent phenomenon (see, e.g., Lee, Tzeng, Garro, \& Hung, 1978). For example, Lee et al. (1978) found that the word frequency effect was not reduced when the study and test modalities (visual vs. auditory) did not match, although the word frequency effect was greater when the study was visual irrespective of the test modality. In contrast to this finding, Jacoby and Dallas (1981, Experiment 6) reported that the low-frequency advantage was greater when the study and test modality matched. However, in their design, the test modality was always visual; hence the match/mismatch in study-test modality and the study modality was confounded. Their finding of a reduced word frequency effect under the mismatch condition (auditory study-visual test) is therefore entirely consistent with Lee et al.'s finding of a reduced word frequency effect when the study modality was auditory. That the low-frequency word advantage in recognition memory tests is unaffected by a mismatch in studytest modality is what would be expected on the basis of the view that the advantage has its origin in conscious recollection rather than perceptual fluency.

The view that feeling of familiarity does not necessarily mirror perceptual fluency is also consistent with the fact that some manipulations that modulate performance on data-driven indirect memory tests failed to produce an effect on know responses in recognition memory tests. For example, changes in modality and generation encoding manipulation are known to reduce performance on perceptual identification and word fragment completion (e.g., Jacoby, 1983; Roediger \& Blaxton, 1987), yet these factors have little effect on know responses (e.g., Gardiner, 1988,
Experiment 2; Rajaram, 1993, Experiment 1). If perceptual fluency had been involved in producing both repetition priming and feelings of familiarity, these manipulations would have produced parallel effects. The fact that these manipulations did not affect know responses suggests that perceptual fluency does not routinely enhance feelings of familiarity.

There is one problem with the preceding view, however. If perceptual fluency does not enhance feelings of familiarity, how can the effects of experimenter-manipulated perceptual fluency on recognition memory tests be explained, when they are found (see earlier discussion of Johnston, Hawley, \& Elliott, 1991, and Watkins \& Gibson, 1988)? An observation reported by Merikle and Reingold (1991) may shed some light here. Merikle and Reingold found evidence of subjects' using perceptual fluency (for words that had been presented under divided attention) only in later blocks but not in early blocks of recognition memory test trials. In their experiment, subjects saw each word against a background mask and were required either to judge the visual clarity of the word (an indirect memory test) or to make a recognition memory judgment (a direct memory test). Merikle and Reingold found that the sensitivity of the direct test exceeded that of the indirect test only in the last of the three blocks of trials. They took this finding to suggest that subjects may have adopted different strategies for performing the recognition memory test across trial blocks. Specifically, in earlier blocks, subjects may have based their decisions on conscious but irrelevant aspects of the task, but over time, they abandoned these ineffective strategies based on consciously available information and simply based their decisions on "general impressions" (which presumably included perceptual fluency indexed by apparent clarity of the item). This explanation is at odds with the view that the attribution of perceptual fluency to the feelings of familiarity is "unconscious" (Jacoby, Kelley, \& Dywan, 1989) and instead suggests that the attribution reflects a deliberate strategy. Perhaps such a deliberate strategy also underlies the findings of effects of experimenter-manipulated perceptual fluency (see, e.g., Johnston et al., 1991; Whittlesea et al., 1990). The fact that these findings were obtained when the relationship between perceptual fluency and recognition memory was made obvious (for example, by requiring subjects to make the recognition memory judgment immediately after identifying the item, rather than making judgments at separate occasions) is consistent with this possibility.

Another finding that is difficult to reconcile with the view that the word frequency effect in recognition memory has its origins in conscious recollection concerns the memory performance of amnesic subjects. As mentioned in the introduction, amnesic Korsakoff patients have been found to show the low-frequency word advantage in recognition memory tests (e.g., Huppert \& Piercy, 1976; Verfaellie et al., 1991). But how can this be when conscious recollection is the very ability that is assumed to be impaired in the amnesic patients? A potential answer to this puzzle is to assume that the bases for making recognition 
memory judgments are not necessarily the same for Korsakoff patients and memory-intact subjects. Specifically, the recognition memory performance for Korsakoff patients is driven largely by fluency of processing. ${ }^{4}$ Support for this view can be found in studies comparing performance on direct and indirect memory tests and observed decoupling in performance in the two types of tests for memory-intact subjects but not Korsakoff patients. For example, Cermak, Verfaellie, Sweeney, and Jacoby (1992) reported that although amnesic and control subjects produced the same amount of repetition priming effects in a word stem completion task, amnesic subjects were less able to avoid completing word stems with previously presented words when instructed to do so. In a similar vein, Mayes, Pickering, and Fairbairn (1987) presented Korsakoff patients and control subjects with two lists of word pairs, pairing the same cue with different target words across lists (e.g., bee-HONEY; bee-STING). Mayes et al. found that the amnesic subjects made the same number of "intrusions" from the first list as control subjects when asked to free associate to cue words, but unlike the controls, they were unable to avoid intrusions in a cued recall test when instructed to respond only from the second list. These studies suggest that amnesic patients rely on the same mechanism that is responsible (fluency of processing) for repetition priming effects for performing a direct memory test. In contrast, for memory-intact subjects, the performance on direct and indirect tests is dissociated when the former demands conscious recollection of the study episode.

Finally, if perceptual fluency does not constitute an adequate cue for a feeling of familiarity, what does serve as a cue? Moscovitch and Bentin (1993) recently proposed that for memory-intact subjects, "Recognition, even when it is based only on a sense of familiarity, is an explicit test of memory" and that "the process that gives rise to a sense of familiarity (insofar as that sense is inextricably a product of the process rather than an inferred or attributed byproduct of it; Jacoby, 1983; Johnston, Dark, \& Jacoby, 1985) is different from the process that is involved in producing repetition effects" (p. 157). They argued that for memoryintact subjects, the effective cue on recognition memory tests is not simply the stimulus itself but the "complex event associated with the stimulus" (p. 156). Presumably such a complex event includes the spatial and temporal context, as well as other information that distinguishes the specific episode in which the item was encountered from other episodes. Bentin, Moscovitch, and Heth (1992) also measured evoked cortical responses in indirect (lexical decision) and direct (recognition) memory tests and found that the effects of lag and recency of repetition in the two tasks were associated with different components of the evoked response. Bentin et al. speculated on the intriguing possibility that one component might be associated with recognition due to familiarity and the other with repetition priming effects in an indirect memory test. Identifying neurological correlates of feelings of famil- iarity and repetition priming effects would be an important goal of future studies.

\section{REFERENCES}

Atkinson, R. C., \& Juola, J. F. (1974). Search and decision processes in recognition memory. In D. H. Krantz, R. C. Atkinson, $R$. D. Luce, \& P. Suppes (Eds.), Contemporary developments in mathematical psychology: Vol. l. Learning, memory and thinking (pp. 243-293). San Francisco: W. H. Freeman

Bentin, S., Moscovitch, M., \& Heth, I. (1992). Memory with and without awareness: Performance and electrophysiological evidence of savings. Journal of Experimental Psychology: Learning, Memory \& Cognition, 18, 1270-1283.

Cermak, L. S., Butters, N., \& Moreines, J. (1974). Some analysis of the verbal encoding deficit of alcoholic Korsakoff patients. Brain \& Language, 1, 141-150.

Cermak, L. S., Verfaellie, M., Sweeney, M., \& Jacoby, L. L. (1992) Fluency versus conscious recollection in the word completion performance of amnesic patients. Brain \& Cognition, 20, 367-377.

ColtheART, M. (1981). The MRC psycholinguistic database. Quarterly Journal of Experimental Psychology, 33A, 497-508.

DuCHEK, J. M., \& NEELY, J. H. (1989). A dissociative word-frequency $\times$ levels-of-processing interaction in episodic recognition and lexical decision tasks. Memory \& Cognition, 17, 148-162.

EICH, E. (1984). Memory for unattended events: Remembering with and without awareness. Memory \& Cognition, 12, 105-111.

ForSTER, K. I., \& DAVIS, C. (1984). Repetition priming and frequency attenuation in lexical access. Journal of Experimental Psychology. Learning, Memory, \& Cognition, 10, 680-698.

FORSTER, K. I., \& FORSTER, J. C. (1990). User's guide to the dmastr display system. Tucson: University of Arizona.

GARDINER, J. M. (1988). Functional aspects of recollective experience. Memory \& Cognition, 16, 309-313.

GARDiner, J. M., \& JAVA, R. I. (1990). Recollective experience in word and nonword recognition. Memory \& Cognition, 18, 23-30.

Gardiner, J. M., \& PARKIn, A. J. (1990). Attention and recollective experience in recognition memory. Memory \& Cognition, 18, 579-583.

Gillund, G., \& Shiffrin, R. M. (1984). A retrieval model for both recognition and recall. Psychological Review, 91, 1-67.

GlanZer, M., \& Adams, J. K. (1985). The mirror effect in recognition memory. Memory \& Cognition, 13, 8-20.

GREGG, V. H. (1976). Word frequency, recognition, and recall. In J. Brown (Ed.), Recall and recognition (pp. 183-216). London: Wiley.

Haist, F., Shimamura, A. P., \& Squire, L. R. (1992). On the relationship between recall and recognition memory. Journal of Experimental Psychology: Learning, Memory, \& Cognition, 18, 691-702.

Huppert, F. A., \& PierCY, M. (1976). Recognition memory in amnesic patients: Effects of temporal context and familiarity of material. Cortex, 12, 3-20.

JACOBY, L. L. (1983). Remembering the data: Analyzing interactive processes in reading. Journal of Verbal Learning \& Verbal Behavior, 22, 485-508.

JACOBY, L. L., \& DALLAS, M. (1981). On the relationship between autobiographical memory and perceptual learning. Journal of Experimental Psychology: General, 110, 306-340.

JACOBY, L. L., KELlEY, C. M., \& DywaN, J. (1989). Memory attributions. In H. L. Roediger III \& F. I. M. Craik (Eds.), Varieties of memory and consciousness: Essays in honour of Endel Tulving (pp. 391422). Hillsdale, $\mathrm{NJ}$ : Erlbaum

Johnston, W. A., DARK, V. J., \& JACOBY, L. L. (1985). Perceptual fluency and recognition judgments. Journal of Experimental Psychology: Learning, Memory, \& Cognition, 11, 3-4.

Johnston, W. A., Hawley, K. J., \& Elliott, J. M. (1991). Contribution of perceptual fluency to recognition judgments. Journal of Experimental Psychology: Learning, Memory, \& Cognition, 17, 210 223.

KELLOGG, R. T. (1980). Is conscious attention necessary for long-term 
storage? Journal of Experimental Psychology: Human Learning \& Memory, 6, 379-390.

KinoshiTA, S. (1989). Masked and unmasked repetition effects: Activation of representation or procedure? In S. Lewandowsky, J. C. Dunn, \& K. Kirsner (Eds.), Implicit memory: Theoretical issues (pp. 213227). Hillsdale, NJ: Erlbaum.

KuČERA, H., \& FrANCIS, W. N. (1967). Computational analysis of presentday American English. Providence, RI: Brown University Press.

Kunst-WILSON, W. R., \& ZAJONC, R. B. (1980, February). Affective discrimination of stimuli that cannot be recognized. Science, 207, 557-558.

Lee, A. T., Tzeng, O. J. L., Garro, L. C., \& Hung, D. L. (1978). Sensory modality and the word-frequency effect. Memory \& Cognition, 6, 306-311.

MaCLeOD, C. M. (1989). Word context during initial exposure influences degree of priming in word fragment completion. Journal of Experimental Psychology: Learning, Memory, \& Cognition, 15, 398-406

MANDLER, G. (1980). Recognizing: The judgment of previous occurrence. Psychological Review, 87, 252-271.

Mandler, G., NaKamura, Y., \& Van Zandt, B. (1987). Nonspecific effects of exposure on stimuli that cannot be recognized. Journal of $E x$ perimental Psychology: Learning, Memory, \& Cognition, 13, 646-648.

Mayes, A. R., Pickering, A., \& Fairbairn, A. (1987). Amnesic sensitivity to proactive interference: Its relationship to priming and the causes of amnesia. Neuropsychologia, 25, 211-220.

MERIKLE, J., \& ReINGOLD, E. (1991). Comparing direct (explicit) and indirect (implicit) measures to study unconscious memory. Journal of $E x$ perimental Psychology: Learning, Memory, \& Cognition, 17, 224-233.

Moscovitch, M., \& Bentin, S. (1993). The fate of repetition effects when recognition approaches chance. Journal of Experimental Psychology: Learning, Memory, \& Cognition, 19, 148-158.

RaJaram, S. (1993). Remembering and knowing: Two means of access to the personal past. Memory \& Cognition, 21, 89-102.

RoEDiger, H. L., III, \& BlaXtoN, T. A. (1987). Retrieval modes produce dissociations in memory for surface information. In D. S. Gorfein \& R. R. Hoffman (Eds.), Memory and cognitive processes: The Ebbinghaus Centennial Conference (pp. 349-379). Hillsdale, NJ: Erlbaum.

RoEdiger, H. L., III, Weldon, S. M., STAdLeR, M. L., \& Riegler, G. L (1992). Direct comparison of two implicit memory tests: Word fragment and word stem completion. Journal of Experimental Psychology: Learning, Memory, \& Cognition, 18, 1251-1269.

SCarborough, D. L., Cortese, C., \& SCarborough, H. S. (1977). Frequency and repetition effects in lexical memory. Journal of Experimental Psychology: Human Perception \& Performance, 3, 1-17.

SKINNER, M., \& GRANT, B. (1992). Generation and frequency effects on repetition priming. Paper presented at the Australian Experimental Psychology Conference, Sydney.

TenPenny, P. L., \& Shoben, E. J. (1992). Component processes and the utility of the conceptually-driven/data-driven distinction. Journal of Experimental Psychology: Learning, Memory, \& Cognition, 18, 25-42.

Tulving, E. (1985). Memory and consciousness. Canadian Psychologist, 26, 1-12.

Verfaellie, M., Cermak, L. S., Letourneau, L., \& Zuffante, P. (1991). Repetition effects in a lexical decision task: The role of episodic memory in the performance of alcoholic Korsakoff patients. Neuropsychologia, 29, 641-657.

WATKINS, M. J., \& Gibson, J. M. (1988). On the relation between perceptual priming and recognition memory. Journal of Experimental Psychology: Learning, Memory, \& Cognition, 14, 477-483.
Whittlesea, B., JaCoBy, L. L., \& GiRARD, K. (1990). Illusions of immediate memory: Evidence of an attributional basis for feelings of familiarity and perceptual quality. Journal of Memory \& Language, 29, 716-732.

Wolford, G., \& Morrison, F. (1980). Processing of unattended visual information. Memory \& Cognition, 8, 521-527.

\section{NOTES}

1. An exception to this pattern has been reported by Tenpenny and Shoben (1992), who found a greater priming for high-frequency than for low-frequency words in the word fragment completion task. In all other studies, however, the baseline performance (i.e., for words that had not been presented at study) was lower for low-frequency words than for high-frequency words. The baseline completion rate in Tenpenny and Shoben's study, however, did not seem to differ between high- and lowfrequency words. As will be discussed in the present paper, the low-frequency advantage in repetition priming reflects a proportionally greater increment of perceptual fluency for low-frequency words due to prior exposure; thus the low-frequency advantage is not necessarily expected when the baseline performance level is not lower for low-frequency words than for high-frequency words.

Forster and Davis (1984) also reported finding equal priming effects for high- and low-frequency words when the words were preceded immediately by masked primes. Because this paradigm is different from the standard paradigm in which study and test phases are separated by a time interval or intervening items, it will not be discussed here. (See Kinoshita, 1989, for a discussion of this effect.)

2 . The finding of a greater repetition priming effect for low- than for high-frequency unattended words in a lexical decision task is at odds with the failure to find such an effect in a previous study (Forster \& Davis, 1984, Experiment 4). In that study, subjects made lexical decisions about words that had been presented earlier as part of a context that did not require responding. Although Forster and Davis reported that the interaction between preexposure and word frequency was nonsignificant, there was a tendency toward a greater repetition priming effect for low-frequency words ( $28 \mathrm{msec}$ ) than for high-frequency words $(8 \mathrm{msec})$. The error rate data, for which no statistical analysis was reported, also showed a similar pattern $(-0.5 \%$ repetition priming for high-frequency words, $6.5 \%$ repetition priming effects for low-frequency words). As Forster and Davis themselves have pointed out, because repetition priming itself was weak, perhaps an interaction between word frequency and preexposure may have been observed with a stronger repetition priming effect.

3. I am grateful to Eyal Reingold for suggesting this possibility.

4. It is also relevant to note that the amnesic subjects who showed superior recognition memory for low-frequency than for high-frequency words were all Korsakoff patients (Huppert \& Piercy, 1976; Verfaellie et al., 1991), who typically have some frontal lobe damage and are often found to be impaired especially on conceptual processing ability (see, e.g., Cermak, Butters, \& Moreines, 1974). It is possible, therefore, that these patients have a particular propensity to rely on perceptual fluency in making recognition memory judgments, which may not be the case with amnesics with different etiologies (see Haist, Shimamura, \& Squire, 1992 , for a related view).

(Manuscript received February 14, 1994 revision accepted for publication August 25, 1994.) 